\title{
An Integrated Conceptual Framework for Adapting Forest Management Practices to Alternative Futures
}

\author{
Tony Prato ${ }^{1}$ and Travis B. Paveglio ${ }^{2}$ \\ ${ }^{1}$ Department of Agricultural and Applied Economics, University of Missouri, Columbia, MO 65211, USA \\ ${ }^{2}$ Department of Conservation Social Sciences, University of Idaho, Moscow, ID 83844, USA \\ Correspondence should be addressed to Tony Prato; pratoa@missouri.edu
}

Received 19 September 2013; Accepted 22 January 2014; Published 12 March 2014

Academic Editor: Hubert Sterba

Copyright (c) 2014 T. Prato and T. B. Paveglio. This is an open access article distributed under the Creative Commons Attribution License, which permits unrestricted use, distribution, and reproduction in any medium, provided the original work is properly cited.

\begin{abstract}
This paper proposes an integrated, conceptual framework that forest managers can use to simulate the multiple objectives/indicators of sustainability for different spatial patterns of forest management practices under alternative futures, rank feasible (affordable) treatment patterns for forested areas, and determine if and when it is advantageous to adapt or change the spatial pattern over time for each alternative future. The latter is defined in terms of three drivers: economic growth; land use policy; and climate change. Four forest management objectives are used to demonstrate the framework, minimizing wildfire risk and water pollution and maximizing expected net return from timber sales and the extent of potential wildlife habitat. The fuzzy technique for preference by similarity to the ideal solution is used to rank the feasible spatial patterns for each subperiod in a planning horizon and alternative future. The resulting rankings for subperiods are used in a passive adaptive management procedure to determine if and when it is advantageous to adapt the spatial pattern over subperiods. One of the objectives proposed for the conceptual framework is simulated for the period 2010-2059, namely, wildfire risk, as measured by expected residential losses from wildfire in the wildland-urban interface for Flathead County, Montana.
\end{abstract}

\section{Introduction}

Maintaining the long-term sustainability of forest ecosystems is challenging due to uncertainty about future changes in socioeconomic, biophysical, and other conditions that influence the achievement of forest management objectives. Several studies have proposed management strategies to enhance the capacity of forest ecosystems to respond or adapt to new or changing conditions or, equivalently, to increase the resilience of forest ecosystems to change [16]. Most studies of this sort focus on how changes in just one condition influence a particular management objective (e.g., how landscape fragmentation resulting from residential development degrades wildlife habitat or how increases in temperature resulting from climate change influence the distribution of tree species). Few studies have assessed how multiple socioeconomic, biophysical, and other conditions influence the multiple objectives for which many forests are managed. This deficiency may be due, in part, to the lack of an integrated conceptual framework that forest managers can use to evaluate the impacts of multiple conditions on multiple forest management objectives and how best to adapt forest management practices to uncertain future changes in those conditions.

This paper proposes an integrated conceptual framework for that purpose. The framework: (1) simulates the multiple objectives achieved by different spatial patterns of forest management practices (or patterns for short) under alternative economic growth, land use policy, and climate change futures; (2) ranks feasible patterns for areas managed by different forest managers; and (3) determines if and when it is advantageous for a forest manager to adapt or change the pattern over time in response to economic growth and changes in land use policy and climate. Empirical results are presented for one of the objectives proposed for the framework. 


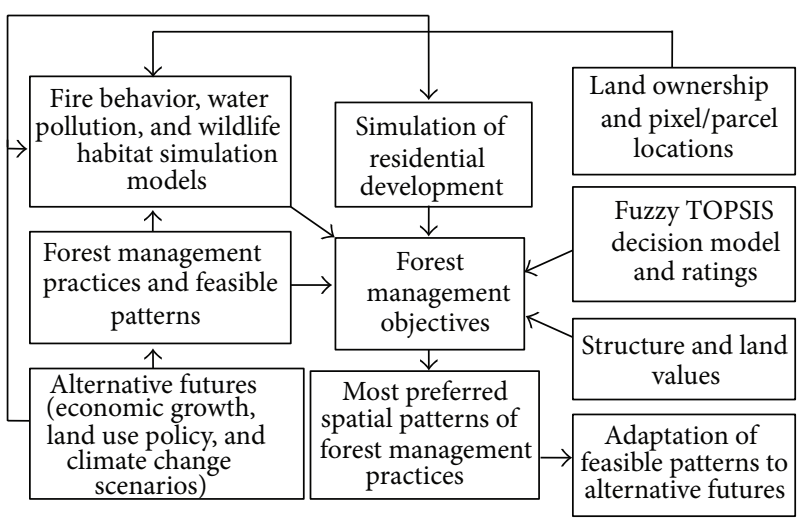

Figure 1: Flow diagram of proposed conceptual framework.

\section{Proposed Framework}

This section begins with an overview of the proposed framework (see Figure 1) followed by detailed descriptions of the submodels for that framework. The framework evaluates spatial patterns of forest management practices in terms of four objectives (1) expected residential losses due to wildfire (E(RLW)), or wildfire risk; (2) water pollution; (3) expected net return from timber sales; and (4) extent of potential wildlife habitat. Several submodels and assumptions are used to simulate E(RLW). Future residential development is simulated using the RECID2 land use change simulation model. Input for that model includes the amount of land required for new residential development, which is simulated using the impact analysis for planning (IMPLAN) regional economic model in combination with the growth rates for economic sectors specified by the economic growth scenario and assumptions about the location and density of new residential development as specified in the land use policy scenario. Changes in vegetation over time are simulated using the FireBGCv2 model, which requires inputting temperature and precipitation projections corresponding to a particular climate change scenario, information on current vegetation, landownership patterns, and forest management practices used by landowners. Vegetation changes over time are inputted to the FSim model to estimate burn probabilities for a forested landscape and conditional probabilities of various flame length categories for smaller areas of the landscape. Several models can be used to simulate water pollution and extent of potential wildlife habitat for different spatial patterns of forest management practices. Estimation of expected net return from timber sales is relatively straightforward once the volume of timber harvested and market prices for logs has been determined. The most preferred spatial patterns of forest management practices are determined by ranking feasible spatial patterns of forest management practices using the simulated values of the four management objectives for those patterns in a multiple attribute evaluation method (i.e., fuzzy technique for preference by similarity to the ideal solutionfuzzy TOPSIS).

Because each of the four objectives depends on a large number of parameters and assumptions, it is infeasible to conduct a sensitivity analysis with respect to all the possible combinations of those parameters and assumptions. Furthermore, there is little basis for choosing which combinations of parameters/assumptions to include in a sensitivity analysis. For those reasons, it is not feasible to analyze how sensitive the preferred spatial pattern of forest management practices for a landscape is to the parameters and assumptions of the framework. Instead, the focus is placed on grounding the assumptions and inputs used in submodels to accurately represent the socioecological landscape being studied (e.g., see the description of methods used to derive data for the simulation of $\mathrm{E}(\mathrm{RLW})$ [7] or the RECID2 model [7, 8]). The alternative futures analysis described in the next section does allow users to evaluate how sensitive the objectives and preferred spatial pattern of forest management practices are to different alternative futures (i.e., different combinations of economic growth, land use policy, and climate change scenarios). For example, the sensitivity of $E(R L W)$ to three different land use policies has been evaluated [7].

2.1. Alternative Futures Analysis. The conceptual framework uses alternative futures analysis (AFA) to account for uncertainty regarding future economic growth, land use policy, and climate change. AFA has been used in several studies conducted in several areas of North America, including Pennsylvania [9], California [10], the Willamette River Basin in Oregon [11, 12], the Upper San Pedro River Basin in Arizona and Sonora, Mexico [13], Wisconsin [14], and Flathead County, Montana [7]. AFA rests on three premises: (1) decision-makers and stakeholders are unsure about what the future will bring (i.e., there is uncertainty); (2) no single vision of the future is likely to be accurate or superior to all others; and (3) impacts of future change need to be evaluated for a range of conditions [13]. AFA does not predict future outcomes. Rather, it evaluates possible future outcomes under particular assumptions.

In this study, an alternative future consisted of a particular combination of an economic growth scenario, land use policy scenario, and climate change scenario for each subperiod in the planning horizon. For example, if the planning horizon is 2014-2063 (50 years) and the subperiods are 10 years long, there are five subperiods: 2014-2023; 2024-2033; 2034-2043; 2044-2053; and 2054-2063. An alternative future is the same throughout the planning horizon.

An economic growth scenario specifies the average annual growth rate over the planning horizon for each economic sector of the regional economy within which the forests of interest are located. Economic growth in each sector creates new jobs. New jobs are converted into new households and new households require housing units to live in and land on which to build those housing units. The number of new jobs associated with a particular growth rate is projected for each subperiod using the IMPLAN regional economic analysis model [15]. The number of new households associated with the number of new jobs is estimated by multiplying the new jobs by a population-to-jobs ratio and dividing by the average persons per household. The resulting increase in households is multiplied by a housing units-to-households 
ratio to estimate the increase in housing units associated with a particular growth rate. The amount of additional land required for additional housing units is determined using the RECID2 model described below.

A land use policy scenario specifies: (1) the percentage of housing units in each of six residential housing density classes; (2) setbacks of houses from wetlands and waterbodies; (3) the type and density of residential development allowed in environmentally sensitive areas (i.e., wetlands, streams, rivers, lakes, ponds, and shallow aquifers) and within and outside of sewer accessible areas; and (4) for example, no development on most public land, on parcels in the 100-year floodplain, and on parcels that have an average slope greater than $30 \%$. As the land use policy scenario becomes more restrictive, the density of houses and setbacks from wetlands and waterbodies increases and the type of development allowed in environmentally sensitive areas becomes more limited. For all three land use policy scenarios, only high, urban, and suburban density housing are allowed on seweraccessible parcels; rural, exurban, and agricultural density housing are allowed on all developable parcels. The six residential density classes and corresponding number of housing units per developed hectare are: (1) high (15.5619.02); (2) urban (12.23-14.94); (3) suburban (3.71-6.18); (4) rural (1.85-3.09); (5) exurban (0.25-0.40); and agricultural (0.040-0.064). The sizes of developed parcels in a residential density class are randomly selected from the ranges of parcel sizes for that density class.

The RECID2 model uses the requirement for additional housing units in each density class, the number and size of parcels available for new residential development, and development attractiveness scores for developable parcels to determine on which parcels in the WUI to place new residences during each subperiod. More details about the RECID2 model are given by Prato et al. [8].

The economic growth and land use policy scenarios for a subperiod influence the spatial extent of the wildland-urban interface (WUI), the number and density of homes in the WUI, and expected residential losses from wildfire for that subperiod. A WUI is the area where residential structures are adjacent to or interspersed with wildland vegetation $[16$, 17]. Expected residential losses from wildfire are the wildfire risk metric used in the decision model for the conceptual framework.

Uncertainty regarding future $\mathrm{CO}_{2}$ mitigation, nonlinear thresholds in the climate system, and limitations of the current generation of climate models leads to uncertainty about future climate change. Such uncertainty influences vegetative growth, forest succession, and the probability of wildfire in a forested landscape. Climate scenarios and associated projections of temperature and precipitation, which are input to the biophysical models (i.e., FireBGCv2 and FSim), are obtained from the International Panel on Climate Change (IPCC)'s fourth assessment [18] or fifth assessment [19]. To apply the IPCC emission scenarios to a forested landscape at the local level (e.g., at the spatial scale of a national forest), requires spatial and temporal downscaling of the IPCC projections of temperature and precipitation for each emission scenario. Currently, the World Climate
Research Program's (WCRP's) Coupled Model Intercomparison Project Phase 5 (CMIP5) [20] provides $12 \mathrm{~km}^{2}$ resolution temperature and precipitation projections for the $\mathrm{A} 1 \mathrm{~B}, \mathrm{~A} 2$, and $\mathrm{B} 1$ emission scenarios. The CMIP data are bias corrected (monthly means adjusted and matched to the observational climate data) and validated against observational data using the two-step process described by Wood et al. [21, 22] and Meehl et al. [23]. Because the biophysical models require daily temperature and precipitation data, the CMIP projections are downscaled to daily temperature and precipitation projections using the delta method $[7,24]$.

2.2. Decision Model. The decision model uses fuzzy TOPSIS to rank the feasible patterns for each subperiod and alternative future. A pattern specifies which forest management practice (e.g., commercial harvesting, mechanical thinning, or prescribed burning) to apply to each pixel managed by a forest manager. A spatial pattern for a subperiod is feasible if total expenditures on forest management practices for that pattern do not exceed the manager's expected budget for forest management practices for that subperiod. Spatial variability in the biophysical characteristics of pixels and differences in the relative importance of objectives across forest managers could cause the ranking of patterns to vary across forest managers. For example, in terms of the relative importance of objectives, the Multiple Use and Sustained Yield Act of 1960 requires the USDA Forest Service to manage their lands for outdoor recreation, range, timber, watershed, and fish, and wildlife with no use greater than any other (i.e., the five uses or objectives are equally important). In contrast, the primary management objective of a private industrial forest manager is to maximize net return from the sale of logs subject to constraints, such as legally mandated best management practices.

Fuzzy TOPSIS is a fuzzy multiple objective decision method that ranks decision alternatives based on their closeness coefficients [25-28]. The latter indicate how close the values of the objectives for a feasible pattern are to the values of the objectives for the fuzzy positive-ideal pattern and how far away they are from the values of the objectives for the fuzzy negative-ideal pattern. The fuzzy positive-ideal pattern has the most desirable values of the objectives and the fuzzy negative-ideal pattern has the least desirable values of the objectives.

Advantages of fuzzy TOPSIS are that, unlike the utility function approach to ranking decision alternatives $[29,30]$, it does not assume utility independence for objectives and a risk-neutral decision-maker. Utility independence implies that the marginal utility of one objective is independent of the amounts of all other objectives. A risk-neutral decisionmaker compares and ranks alternatives based solely on their expected values.

Application of fuzzy TOPSIS requires: (1) determining which objectives are positive (i.e., more is preferred to less of the objective) or negative (i.e., less is preferred to more of the objective); and (2) selecting narrative descriptions or linguistic variables for both the values of the management 
objectives and their relative importance. For example, suppose patterns are characterized in terms of four management objectives: wildfire risk; water pollution; net return from the sale of wood products; and extent of potential wildlife habitat. Wildfire risk and water pollution are negative objectives and the sale of wood products and extent of potential wildlife habitat are positive objectives.

In order to rank patterns using fuzzy TOPSIS, forest managers must first rate the simulated values and the relative importance of the attributes. A convenient way to do such ratings is to assign triangular fuzzy numbers to the linguistic variables used in the ratings. A triangular fuzzy number is designated as $T(a, b, c)$, or simply $(a, b, c)$, where $a$ is the minimum value, $b$ is the mode, and $c$ is the maximum value of the triangular probability distribution (Figure 2).

Table 4 is an example of assigning triangular fuzzy numbers to linguistic variables for rating the simulated values of objectives.

Similarly, Table 5 is an example of how to assign triangular fuzzy numbers to linguistic variables for rating the relative importance of objectives.

The triangular fuzzy numbers appearing in Tables 4 and 5 are variants of the ones proposed by Chen [27].

Ratings of the values and relative importance of attributes can be done by either individual members of a management team or the team as a whole. If ratings are done by individual members, then the fuzzy numbers corresponding to the linguistic variables assigned by individual members are averaged to obtain fuzzy numbers for the management team. For example, if the triangular fuzzy numbers corresponding to the linguistic variables assigned to a particular attribute by the first and second member of the management team are $\left(a_{i j}^{(1)}, b_{i j}^{(1)}, c_{i j}^{(1)}\right)$ and $\left(a_{i j}^{(2)}, b_{i j}^{(2)}, c_{i j}^{(2)}\right)$, respectively, then the average triangular fuzzy number for the attribute (i.e., $\left(a_{i j}^{(1)}+\right.$ $\left.\left.a_{i j}^{(2)}\right) / 2,\left(b_{i j}^{(1)}+b_{i j}^{(2)}\right) / 2,\left(c_{i j}^{(1)}+c_{i j}^{(2)}\right) / 2\right)$ is used in the fuzzy TOPSIS. If the assignment of linguistic variables is done by the management team as a whole, then the fuzzy numbers corresponding to those assignments are used in the fuzzy TOPSIS.

If there are $n_{t}$ feasible spatial patterns for subperiod $t$, then the fuzzy TOPSIS ranks those patterns based on the following closeness coefficients:

$$
C_{i}=\frac{d_{i}^{-}}{d_{i}^{+}+d_{i}^{-}} \quad\left(0 \leq C_{i} \leq 1, i=1, \ldots, n_{t}\right),
$$

where $d_{i}^{+}$is the vertex distance between pattern $i$ and the positive-ideal solution $\left(v_{j}^{+}\right)$, and $d_{i}^{-}$is the vertex distance between pattern $i$ and the negative-ideal solution $\left(v_{j}^{-}\right)$. Vertex distances are calculated as follows:

$$
\begin{aligned}
& d_{i}^{+}=\sum_{j=1}^{4} d\left(w_{j} r_{i j}, v_{j}^{+}\right), \\
& d_{i}^{-}=\sum_{j=1}^{4} d\left(w_{j} r_{i j}, v_{j}^{-}\right) .
\end{aligned}
$$

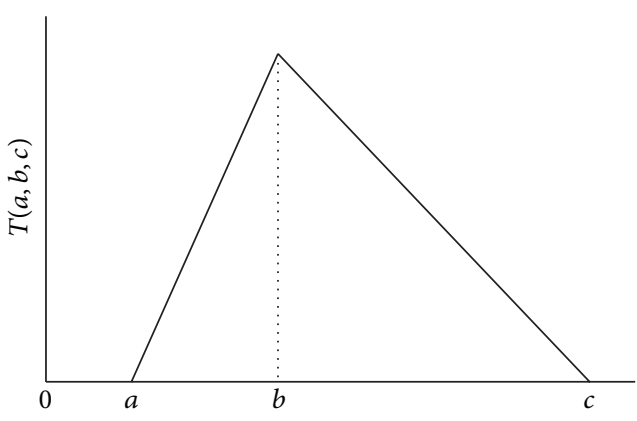

Figure 2: Triangular fuzzy number.

$d(\cdot)$ is the vertex distance operator. For example, $d\left(w_{j} r_{i j}, v_{j}^{+}\right)$ is the vertex distance between the weighted normalized fuzzy effect of pattern $j$ on objective $i$ and the positiveideal solution. For two fuzzy numbers, $z_{1}=\left(e_{1}, e_{2}\right)$ and $z_{2}=\left(k_{1}, k_{2}\right)$, the vertex distance is $d\left(z_{1}, z_{2}\right)=$ $\left\{0.33\left[\left(e_{1}-k_{1}\right)^{2}+\left(e_{2}-k_{2}\right)^{2}\right]\right\}^{0.5}$. For the four attributes considered here, $v_{j}^{+}=(0,0)$ and $v_{j}^{-}=(1,1)$ for wildfire risk and water pollution and $v_{j}^{+}=(1,1)$ and $v_{j}^{-}=(0,0)$ for net return from the sale of wood products and the extent of potential wildlife habitat. The closer (or farther away) $C_{i}$ is to (or from) one, the more desirable (or less desirable) is pattern $i$. Closeness coefficients are used to rank feasible patterns from most desirable to least desirable in descending order of their closeness coefficients. The preferred feasible pattern for a forest manager is the one whose closeness coefficient is nearest to one. For an application of fuzzy TOPSIS, see Prato $[31,32]$.

2.3. Simulating Objectives. This section describes the procedures used to simulate the four objectives considered here. Because there has been considerable research on evaluating the impacts of forest management practices on water quality and the extent of potential wildlife habitat, simulation of net return is relatively straightforward, and little research has been done on simulating wildfire risk; the explanation of the procedures used to simulate wildfire risk is more extensive than the explanations of the procedures used to simulate water quality, extent of potential wildlife habitat, and net return.

2.3.1. Wildfire Risk. Wildfire risk is defined as expected residential losses from wildfire in the WUI or E(RLW) for short. E(RLW) is simulated at the spatial scale of individual residential properties. That choice of spatial scales allows $\mathrm{E}(\mathrm{RLW})$ to be aggregated to larger spatial scales, such as neighborhoods or the WUI as a whole. Simulation of E(RLW) requires information about: (1) housing units that exist at the beginning of the planning horizon (i.e., existing residential properties); (2) number of new housing units added in each subperiod; (3) location and density of new housing units; (4) effects of climate change on growth in forest vegetation and burn probabilities for residential properties; (5) residential homeowners' choices regarding vegetation management in 
the Home Ignition Zone (HIZ) and building materials used in residential structures; and (6) spatial extent of the WUI.

$\mathrm{E}(\mathrm{RLW})$ for the WUI is defined as

$$
\mathrm{E}(\mathrm{RLW})=\mathrm{E}_{d}(\mathrm{RLW})+\mathrm{E}_{w}(\mathrm{RLW}),
$$

where $\mathrm{E}_{d}(\mathrm{RLW})$ is present value in the base year of $\mathrm{E}$ (RLW) for existing residential properties and $\mathrm{E}_{w}(\mathrm{RLW})$ is present value in the base year of $\mathrm{E}(\mathrm{RLW})$ for new residential properties added during the planning horizon.

The base year is the first year in the planning horizon. $\mathrm{E}_{d}(\mathrm{RLW})$ is defined as

$$
\begin{aligned}
\mathrm{E}_{d}(\mathrm{RLW})=\mathrm{PV}_{b}\left[\mathrm{E}_{d 1}(\mathrm{RLW}), \mathrm{E}_{d 2}(\mathrm{RLW}),\right. \\
\left.\mathrm{E}_{d 3}(\mathrm{RLW}), \mathrm{E}_{d 4}(\mathrm{RLW}), \mathrm{E}_{d 5}(\mathrm{RLW})\right],
\end{aligned}
$$

where $\mathrm{PV}_{b}$ stands for present value in the base year. $\mathrm{E}_{d t}(\mathrm{RLW})$ is undiscounted expected wildfire losses for existing residential properties during subperiod $t$ defined as

$$
\begin{aligned}
& \mathrm{E}_{d t}(\mathrm{RLW}) \\
& =\sum_{j=1}^{m_{d}} \mathrm{pb}_{j t}\left[\left(\sum_{h=1}^{n_{d j}} \mathrm{pS}_{h j t} \mathrm{VS}_{d h j t}\right)+\beta_{j t} \mathrm{TV}_{d j t}\right],
\end{aligned}
$$

where $m_{d}$ is the number of parcels in the WUI containing existing residential properties; $n_{d j}$ is the number of existing residential properties in parcel $j ; \mathrm{pb}_{j t}$ is the probability that parcel $j$ burns during subperiod $t ; \mathrm{pS}_{h j t}$ is the probability that structures on property $h$ in parcel $j$ burn during subperiod $t$ given parcel $j$ burns during subperiod $t$; is the total value of existing structure(s) on residential property $h$ in parcel $j$ during period $t ; \beta_{j t}$ is the average percentage loss in aesthetic value of residential properties in parcel $j$ during subperiod $t$ given parcel $j$ burns during subperiod $t$; and $\mathrm{TV}_{d j t}$ is the total value of each existing residential property (structure and land) in parcel $j$ during subperiod $t$.

$n_{d j}$ is determined using computer-assisted mass appraisal (CAMA) data or similar data for the WUI. CAMA data are typically used to keep track of property values and assessments and determine annual property taxes. $\mathrm{pb}_{j t}$ is simulated using the FireBGCv2 and FSim models [33, 34]. FireBGCv2 simulates future changes in forest vegetation for forest stands in the area of interest under a particular climate change scenario and the management practices typically used by landowners. The FSim model uses the outputs of the FireBGCv2 model to estimate burn probabilities for $90 \mathrm{~m}^{2}$ pixels in a forested landscape and conditional probabilities of various flame length categories given pixel burns.

$\mathrm{pS}_{h j t}$ is simulated using the procedures described by Prato et al. [35]. $\mathrm{VS}_{d h j t}$ is the total value of all existing structures or buildings located on residential property $h$ in parcel $j$ during subperiod $t$. It is estimated by $\mathrm{VS}_{d h j t}=(1+\lambda)^{q} \mathrm{VS}_{d h j o}$, where $\mathrm{VS}_{d h j o}$ is the total value of existing structures located on residential property $h$ in parcel $j$ in the first year of the planning horizon determined from the CAMA (or similar) data for that year. $\lambda$ is the assumed annual average growth in property values in the WUI over the planning horizon. $\beta_{j t}$ is estimated using research results from Stetler et al. [36] on aesthetic property values and reductions in property values following wildfire, information about wildfire impacts on property values obtained from property assessors, and the flame length outputs of the FSim model $[34,37]$. A geographic information system (GIS) is used to derive weighted average flame length intensities for parcels and determine one of four fixed amounts of aesthetic property value losses given the average flame length for that parcel [35]. $\mathrm{TV}_{d j t}$ is simulated by $\mathrm{TV}_{d j t}=(1+\lambda)^{q} \mathrm{TV}_{d j o}$, where $\mathrm{TV}_{d j o}$ is the sum of the assessed building and land values for existing residential properties located on parcel $j$ at the beginning of the planning horizon, and $\lambda$ and $q$ are defined above. $\left(\mathrm{pS}_{h j t}\right)\left(\mathrm{VS}_{d h j t}\right)$ is expected wildfire-related loss in the value of the existing structures located on residential property $h$ in parcel $j$ during subperiod $t$. $\left(\beta_{j t}\right)\left(\mathrm{TV}_{d j t}\right)$ is expected wildfire-related loss in the aesthetic value of existing residential properties (including structures and land) located on parcel $j$ during subperiod $t$ given parcel $j$ burns during period $t$.

$\mathrm{E}_{w}(\mathrm{RLW})$ is defined as

$$
\begin{gathered}
\mathrm{E}_{w}(\mathrm{RLW})=\mathrm{PV}_{b}\left[\mathrm{E}_{w}^{(1)}(\mathrm{RLW}), \mathrm{E}_{w}^{(2)}(\mathrm{RLW}), \mathrm{E}_{w}^{(3)}(\mathrm{RLW}),\right. \\
\left.\mathrm{E}_{w}^{(4)}(\mathrm{RLW}), \mathrm{E}_{w}^{(5)}(\mathrm{RLW})\right]
\end{gathered}
$$

where $\mathrm{E}_{w}^{(t)}(\mathrm{RLW})$ is the present value in the base year of expected wildfire losses during the planning horizon for new residential properties added during subperiod $t$. It is defined as

$$
\mathrm{E}_{w}^{(t)}(\mathrm{RLW})=\mathrm{PV}_{t}\left[\mathrm{E}_{w t}(\mathrm{RLW})+\cdots+\mathrm{E}_{w(t+k)}(\mathrm{RLW})\right]
$$

where $\mathrm{PV}_{t}$ is the present value at the end of subperiod $t, k$ equals 4 for $t=1$ (first subperiod), 3 for $t=2$ (second subperiod), 2 for $t=3$ (third subperiod), and so forth. $\mathrm{E}_{w t}(\mathrm{RLW})$ is $\mathrm{E}(\mathrm{RLW})$ at the end of subperiod $t$ for new residential properties added during subperiod $t . \mathrm{E}_{w t}(\mathrm{RLW})$ is defined as

$$
\mathrm{E}_{w t}(\mathrm{RLW})=\sum_{j=1}^{m_{w t}} \mathrm{pb}_{j t}\left[\left(\sum_{h=1}^{n_{w j t}} \mathrm{pS}_{h j t} \mathrm{VS}_{w h j t}\right)+\beta_{j t} \mathrm{TV}_{w j t}\right],
$$

where $m_{w t}$ is the number of parcels in the WUI in which new residential properties are added during subperiod $t ; n_{w j t}$ is the number of new residential properties added to parcel $j$ during subperiod $t ; \mathrm{pb}_{j t}$ is the probability that parcel $j$ burns during subperiod $t ; \mathrm{pS}_{h j t}$ is the probability that structures on property $h$ in parcel $j$ burn during subperiod $t$ given parcel $j$ burns during subperiod $t$; $\mathrm{VS}_{w h j t}$ is the total value of new structures added to residential property $h$ in parcel $j$ during subperiod $t ; \beta_{j t}$ is the average percentage of loss in aesthetic value of residential properties in parcel $j$ during subperiod $t$ given parcel $j$ burns during subperiod $t$; and $\mathrm{TV}_{w j t}$ is the total value of structures and land for a new residential property added to parcel $j$ during subperiod $t$.

$n_{w k t}$ is determined using the RECID2 model described in Section 2.1. Other parameters in (8) are estimated using 
procedures similar to the ones used to estimate the corresponding parameters in (1). $\mathrm{VS}_{w h j t}$ and $\mathrm{TV}_{w j t}$ are simulated using a linked geospatial database of existing property and structure values stratified across neighborhoods in the WUI. Each new residential property added during a subperiod is assigned an appreciated value for the structure(s) on that property and a per hectare land value. Both structure and per hectare land values are drawn randomly from either waterfront or nonwaterfront properties in the same neighborhood within a WUI.

\subsubsection{Water Pollution. Different forest management practices} leave different amounts of vegetative cover on a landscape, which influence the runoff rates to waterbodies located downslope of that landscape. For example, commercial harvesting is likely to cause higher soil erosion rates and sedimentation of downslope waterbodies than mechanical thinning. Sediment loads to waterbodies affect the quality of habitat for aquatic species. In addition, water pollution is influenced by the amount and timing of runoff, which is influenced by climate change.

Several biophysical models can be used to simulate water quality for different land uses or land covers. For example, the Soil and Water Assessment Tool (SWAT) was used to simulate the effects of forest management practices on water hydrology, water quality, and ecosystem services [38, 39]. Using SWAT to simulate the impacts of forest management practices and climate change on water quality requires delineating watersheds and running SWAT for each watershed.

2.3.3. Expected Net Return. Expected net return for a pattern equals the expected total revenue from selling the marketable biomass removed by the forest management practices that make up that pattern, if any, minus the cost of the forest management practices for that pattern. Calculating expected net return requires projecting wood product prices and costs of forest management practices for each subperiod. Wood product prices are market determined and unlikely to vary across forest managers. The cost of a pattern is the sum, overall management practices used in that pattern, of the product of cost per hectare of a forest management practice and the number of hectares to which that practice is applied. Per hectare costs are likely to vary across pixels, even for the same practice, due to spatial variability in slope, aspect, initial forest biomass, forest biomass removed, new road construction and hauling distances (if any), labor and equipment requirements, and other factors. The cost of a pattern is estimated using models, such as the harvest cost model [40].

2.3.4. Extent of Potential Wildlife Habitat. Different patterns of forest management practices and climate projections are likely to have different effects on the extent of potential habitat for wildlife species. For example, forest management practices that open up the forest canopy allow more sunlight to reach the forest floor, which stimulates production of grasses and shrubs and improves habitat for herbivores, such as deer and elk. Open logging roads in prime habitat areas for grizzly bear increase interactions between humans and grizzly bear, which tends to increase grizzly bear mortality [2]. Projected changes in temperature and precipitation corresponding to different climate change scenarios can have positive or negative impacts on the extent of potential wildlife habitat depending on the species [41].

Effects of the spatial pattern of forest management practices and climate change on the extent of potential wildlife habitats can be evaluated by combining land cover/land use data or landscape metrics for each pattern, temperature and precipitation projections for each climate change scenario, and species distribution and persistence models for various species (e.g., [1, 42, 43]). Landscape metrics can be calculated using computer programs such as FRAGSTATS [44] or APACK [45]. For example, Thoma and Shovic [46] assessed the potential impacts of future climate change on three species by identifying spatial habitat characteristics and extent of present-day occurrence of the species, using the lapse rate to predict elevations that are likely to provide favorable temperatures for the species in 2100 (based on climate projections for the IPCC A2 and B1 emission scenarios), employing species distribution and persistence models to map the resulting extent of current and future potential habitat for the species and comparing the two extents to determine whether the extent of potential habitat for the species increases or decreases.

2.4. Rating Values and Relative Importance of Objectives. Application of fuzzy TOPSIS requires each member of a forest management team or the team as a whole to rate the simulated values and relative importance of objectives using linguistic variables. The task of rating the relative importance of objectives using linguistic variables is relatively straightforward. However, the task of rating simulated values of the objectives can be onerous, especially when there are numerous feasible patterns and/or management objectives. Rating of objectives can be simplified by asking each member of a management team or the team as a whole to: (1) consider an index number for the simulated values of each objective where the range of the index number is $[0,100]$; and (2) divide the range for each objective into nonoverlapping intervals where each interval represents a unique linguistic variable (e.g., $0-35$ is very low, $36-55$ is low, 56-75 is medium, 7185 is high, and $86-100$ is very high). Intervals can vary across objectives and individual members of the management team. The intervals are used to assign linguistic variables to simulated values of objectives. For example, if the simulated value of $\mathrm{E}(\mathrm{RLW})$ is 75 for a particular pattern, then $\mathrm{E}(\mathrm{RLW})$ for that pattern is high based on the intervals defined above. Once linguistic variables have been assigned to the simulated values of all objectives and their relative importance, they are assigned to triangular fuzzy numbers using schemes such as the ones given in Section 2.2.

2.5. Adaptive Management. AM postulates that if human understanding of nature is imperfect, then human interactions with nature (e.g., application of forest management practices) should (ideally) be experimental [47]. Kohm and 
TABLE 1: Simulated subperiod areas of parcels required for and converted to six residential housing density classes, Flathead County, Montana, in hectares.

\begin{tabular}{|c|c|c|c|c|c|}
\hline \multirow{2}{*}{ Housing density class } & \multicolumn{5}{|c|}{ Subperiod } \\
\hline & 2010-2019 & 2020-2029 & 2030-2039 & 2040-2049 & 2050-2059 \\
\hline \multicolumn{6}{|l|}{ Required } \\
\hline High & 61 & 67 & 74 & 82 & 92 \\
\hline Urban & 78 & 85 & 94 & 105 & 117 \\
\hline Suburban & 351 & 384 & 424 & 470 & 525 \\
\hline Rural & 898 & 982 & 1,083 & 1,202 & 1,343 \\
\hline Exurban & 6,150 & 6,727 & 7,416 & 8,232 & 9,196 \\
\hline Agricultural & 29,363 & 32,119 & 35,408 & 39,306 & 43,908 \\
\hline \multicolumn{6}{|l|}{ Converted } \\
\hline High & 62 & 67 & 75 & 83 & 92 \\
\hline Urban & 78 & 88 & 95 & 105 & 118 \\
\hline Suburban & 354 & 385 & 433 & 473 & 778 \\
\hline Rural & 923 & 983 & 1,089 & 1,203 & 1,357 \\
\hline Exurban & 6,163 & 6,734 & 7,425 & 8,234 & 9,199 \\
\hline Agricultural & 29,556 & 32,233 & 35,579 & 39,329 & 37,769 \\
\hline
\end{tabular}

TABLE 2: Simulated number of WUI parcels, area of WUI parcels, number of WUI residential structures, and area of the WUI for Flathead County, 2010 and five subperiods.

\begin{tabular}{|c|c|c|c|c|c|c|c|c|}
\hline Subperiod & $\begin{array}{l}\text { Number of } \\
\text { WUI parcels }\end{array}$ & $\begin{array}{l}\% \text { change } \\
\text { between } \\
\text { subperiods }\end{array}$ & $\begin{array}{c}\text { Area of WUI } \\
\text { parcels (ha) }\end{array}$ & $\begin{array}{l}\text { \% change } \\
\text { between } \\
\text { subperiods }\end{array}$ & $\begin{array}{c}\text { Number of WUI } \\
\text { residential } \\
\text { structures }\end{array}$ & $\begin{array}{c}\% \text { change } \\
\text { between } \\
\text { subperiods }\end{array}$ & $\begin{array}{l}\text { Area of the } \\
\text { WUI (ha) }\end{array}$ & $\begin{array}{l}\% \text { change } \\
\text { between } \\
\text { subperiods }\end{array}$ \\
\hline 2010 & 15,761 & - & 41,014 & - & 15,766 & - & 294,344 & - \\
\hline 2010-2019 & 16,463 & 4 & 67,820 & 65 & 20,368 & 29 & 307,434 & 4 \\
\hline $2020-2029$ & 17,099 & 4 & 88,034 & 30 & 25,055 & 23 & 323,563 & 5 \\
\hline $2030-2039$ & 17,786 & 4 & 121,413 & 38 & 30,007 & 20 & 359,329 & 11 \\
\hline 2040-2049 & 18,439 & 4 & 164,947 & 36 & 35,246 & 18 & 402,689 & 12 \\
\hline $2050-2059$ & 19,117 & 4 & 202,410 & 23 & 42,071 & 19 & 426,353 & 6 \\
\hline 2010-2059 & 3,356 & - & 161,396 & - & 26,305 & - & 132,009 & - \\
\hline
\end{tabular}

Franklin state that adaptive management is the only logical approach under the circumstances of uncertainty and the continued accumulation of knowledge [48, page 2]. The primary source of uncertainty for the decision problem considered here is that forest managers do not know which alternative future is most likely to occur (i.e., probabilities cannot be assigned to alternative futures).

AM can be either passive or active. For the current application, active AM would involve using statistically valid experiments to test hypotheses about how changes in economic growth, land use policy, and climate influence the management objectives achieved by different forest management practices or patterns and determine the best way to adapt forest management practices or patterns to those changes based on the results of the experiments. Although active AM does and passive AM does not provide statistically reliable results, active AM is more difficult and expensive to apply than passive AM.

The proposed conceptual framework utilizes passive AM to determine if and when a forest manager should adapt the pattern in response to economic growth, changes in land use policy, and climate change. Passive AM requires a forest manager to: (1) formulate models of how a forested ecosystem is likely to respond to certain exogenous variables; (2) select the preferred pattern for each subperiod based on the models; and (3) determine whether to change or adapt the pattern over subperiods. The first step involves using the FireBGCv2 and FSim models to simulate fire behavior and burn probabilities for each climate change scenario and subperiod, using RECID2 to simulate changes in residential development in each subperiod for each economic growth/land use policy scenario, and fuzzy TOPSIS to rank the feasible patterns for each subperiod and alternative future. Economic growth, land use policy, and climate change are treated as exogenous variables because changes in these variables are determined, for the most part, by conditions over which local forest managers have little influence.

The second step involves selecting management objectives, rating the simulated values and relative importance of the objectives, and using fuzzy TOPSIS to rank the feasible 
TABLE 3: Nominal and inflation-adjusted simulated total E(RLW) and weighted mean $\mathrm{E}(\mathrm{RLW})$ for residential properties in the Flathead County WUI, by subperiod.

\begin{tabular}{lccc}
\hline Subperiod & Total E(RLW) & Percent increase & $\begin{array}{c}\text { Weighted mean } \\
\text { E(RLW) }\end{array}$ \\
\hline \multicolumn{3}{c}{ Nominal dollars } \\
2000-2009 & $1,836,816$ & 0 & 118 \\
$2010-2019$ & $2,539,544$ & 38 & 125 \\
$2020-2029$ & $6,050,600$ & 138 & 241 \\
$2030-2039$ & $13,351,965$ & 120 & 444 \\
$2040-2049$ & $27,761,390$ & 62 & 617 \\
$2050-2059$ & $33,872,543$ & 55 & 805 \\
\hline & \multicolumn{2}{c}{ Inflation-adjusted dollars } \\
$2000-2009$ & $1,836,816$ & 0 & 118 \\
$2010-2019$ & $1,938,584$ & 6 & 95 \\
$2020-2029$ & $4,234,429$ & 117 & 169 \\
$2030-2039$ & $6,014,398$ & 42 & 200 \\
$2040-2049$ & $7,503,927$ & 24 & 213 \\
$2050-2059$ & $8,937,346$ & 19 & 212 \\
\hline
\end{tabular}

TABle 4: Assignment of triangular fuzzy numbers to linguistic variables for rating simulated value of objectives.

\begin{tabular}{lc}
\hline Linguistic variable & Triangular fuzzy number \\
\hline very low & $(0,0,1)$ \\
low & $(0,1,3)$ \\
medium & $(3,5,7)$ \\
high & $(7,8,9)$ \\
very high & $(9,10,10)$ \\
\hline
\end{tabular}

TABLE 5: Assignment of triangular fuzzy numbers to linguistic variables for rating relative importance objectives.

\begin{tabular}{lc}
\hline Linguistic variable & Triangular fuzzy number \\
\hline very low & $(0,0,0.1)$ \\
low & $(0,0.1,0.3)$ \\
medium & $(0.3,0.5,0.7)$ \\
high & $(0.7,0.8,0.9)$ \\
very high & $(0.9,1.0,1.0)$ \\
\hline
\end{tabular}

patterns for each subperiod and alternative future. The preferred pattern for a subperiod and alternative future is the feasible pattern with the highest rank.

The third step involves determining if and when it is advantageous for a forest manager to adapt a pattern to changes in the exogenous variables across subperiods. To illustrate the third step, consider a forest manager that has identified five feasible patterns and fuzzy TOPSIS indicates that the preferred patterns for a particular alternative future are pattern 2 in the first and second subperiods, pattern 1 in the third and fourth subperiods, and pattern 5 in the fifth subperiod. These results imply that the forest manager should undertake the following adaptations over subperiods: (1) use pattern 2 in the first two subperiods; (2) switch from pattern
2 to pattern 1 in the third subperiod; (3) continue pattern 1 in the fourth period; and (4) switch from pattern 1 to pattern 5 in the fifth subperiod.

\section{Results}

Only a portion of the conceptual framework proposed here has been implemented, namely, simulation of the inputs to $\mathrm{E}(\mathrm{RLW})$ and the values of $\mathrm{E}(\mathrm{RLW})$ for the WUI in Flathead County, Montana. Simulations were based on: (1) five, 10-year subperiods (2010-2019, 2020-2029, 2030-2039, 2040-2049, and 2050-2059) covering the planning horizon 2010-2059; (2) an economic growth scenario that assumes an annual average rate of growth of $2.2 \%$ for the Flathead economy; (3) a land use policy for Flathead County that existed in 2010 and a distribution of new housing units among the six residential density classes of high-3\%, urban-18\%, suburban-42\%, rural-6\%, and agricultural-12\%; and (4) climate projections corresponding to the IPCC A2 emission scenario [18]. Scenarios for economic growth, land use policy, and climate change were assumed to remain constant across the five subperiods. The remainder of this section reports subperiod simulation results for: (1) residential development in the WUI; (2) parcel burn probabilities; (3) four WUI metrics; and (4) E(RLW) for the entire WUI. Simulated areas of parcels required for and converted to the six residential housing density classes for each subperiod are given in Table 1.

Figure 3 illustrates the simulated growth in residential development for parcels in the WUI and the spatial extent of the WUI from 2010 to 2059 for Flathead County. Because rural, exurban, and agricultural development occurs at relatively low densities, between $98 \%$ and $99 \%$ of the land area converted to new residential properties occurred at those densities. As expected, the area required for and converted to residential development increases over subperiods. Areas required for and converted to residential housing are the same (apart from differences caused by the discrete size of parcels) for all housing density classes and subperiods except the agricultural housing density class in the last subperiod. In that case, area required is 6,139 hectares greater than area converted because of the lack of developable parcels suitable for residential development at the agricultural housing density.

Burn probabilities for developed parcels for the five, 10year subperiods ending in 2009, 2019, 2029, 2039, 2049, and 2059 are illustrated in Figure 4. Parcel-level burn probabilities are highest and increase the most over subperiods in the southwest portion of the county. A greater proportion of the county is exposed to higher burn probabilities at the end (2059) than at the beginning (2010) of the planning horizon. For instance, burn probabilities for large areas in the north central portion of the county increase over subperiods. In general, there is considerable spatial and temporal variability in the magnitude of the parcel-level burn probabilities.

Table 2 contains the actual and simulated number of WUI parcels, area of WUI parcels, number of WUI residential structures, and area of the WUI in 2010 and the five subperiods. Subperiod increases in the four WUI metrics are 


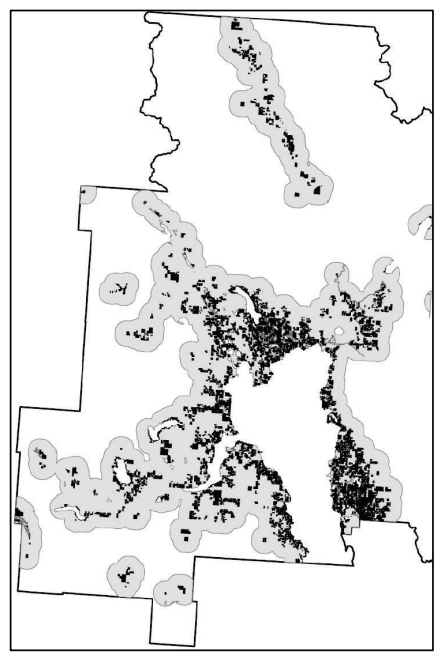

2010 WUI parcels 2010 WUI

Flathead country

(a)

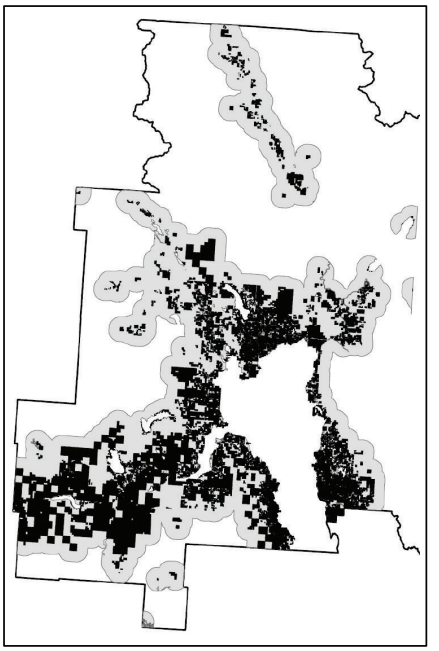

2039 WUI parcels 2039 WUI

Flathead country

(d)

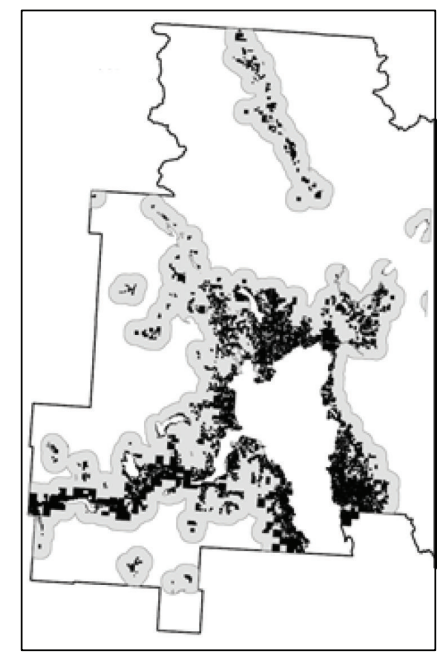

2019 WUI parcels 2019 WUI

Flathead country

(b)

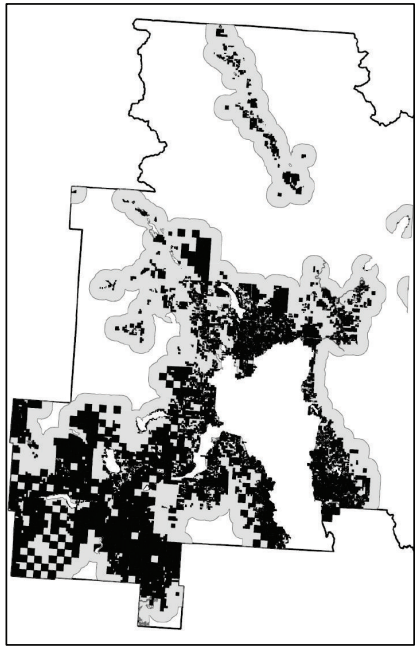

2049 WUI parcels 2049 WUI

Flathead country

(e)

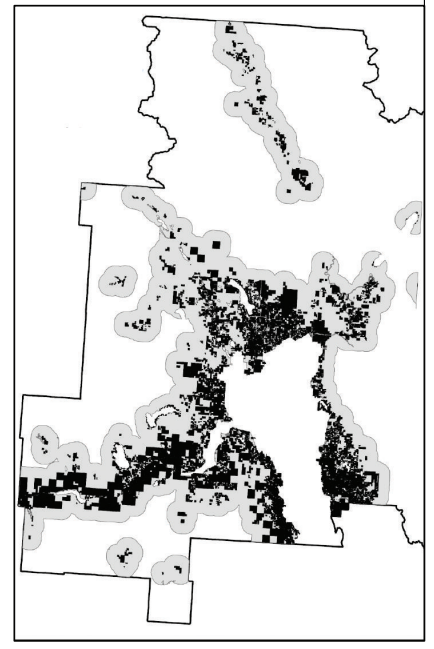

2029 WUI parcels 2029 WUI Flathead country

(c)

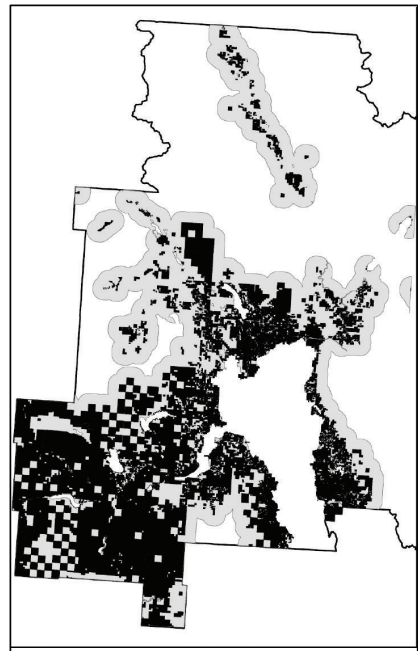

2059 WUI parcels 2059 WUI

Flathead country

(f)

FIgURE 3: Simulated residential development of parcels in the WUI (dark areas) and the spatial extent of the WUI (light gray areas) for Flathead County, Montana, in 2010, and five subperiods.

$4 \%$ for number of WUI parcels, $23 \%$ to $65 \%$ for the area of WUI parcels, $18 \%$ to $29 \%$ for the number of WUI residential structures, and $4 \%$ to $12 \%$ for the area of the WUI. Between 2010 and 2059, the number of WUI parcels increased 21\%, the area of WUI parcels increased 393\%, the number of WUI residential structures increased $167 \%$, and the area of the WUI (or WUI extent) increased 45\%. Subperiod increases in the number of WUI parcels were relatively small because the RECID2 model allows parcels developed at lower housing densities to be subdivided into higher density parcels as the requirement for residential housing increases over time. The WUI extent in 2010 and each subperiod appear as light gray areas in Figure 3.

Of the four WUI metrics, the area of WUI parcels increases the most across subperiods because of the substantial increase over time in the amount of land converted to residential development at the rural, exurban, and agricultural housing densities. Development at these housing densities requires more land than development at the other housing densities. 


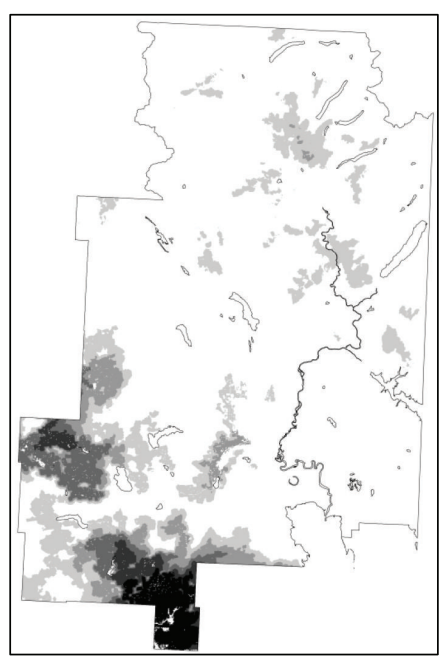

Burn probability 2009

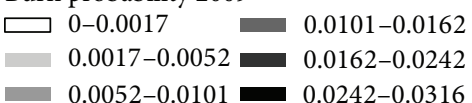

(a)

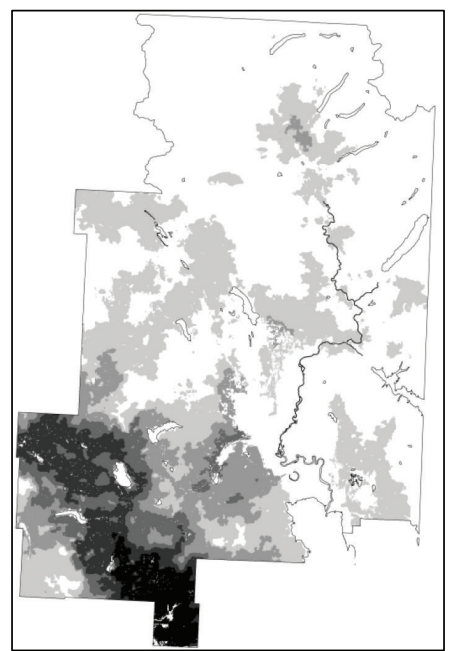

Burn probability 2039

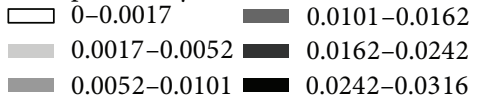

(d)

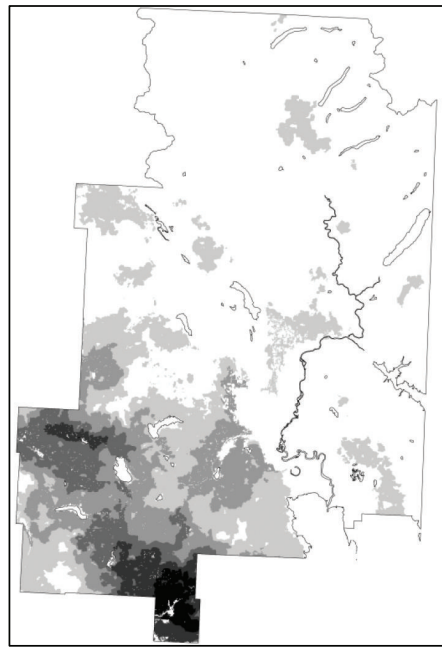

Burn probability 2019

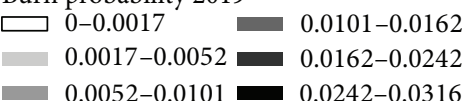

(b)

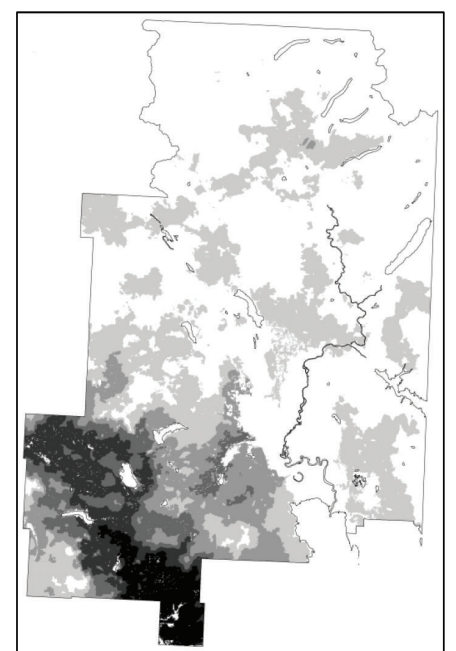

Burn probability 2049

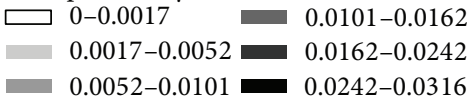

(e)
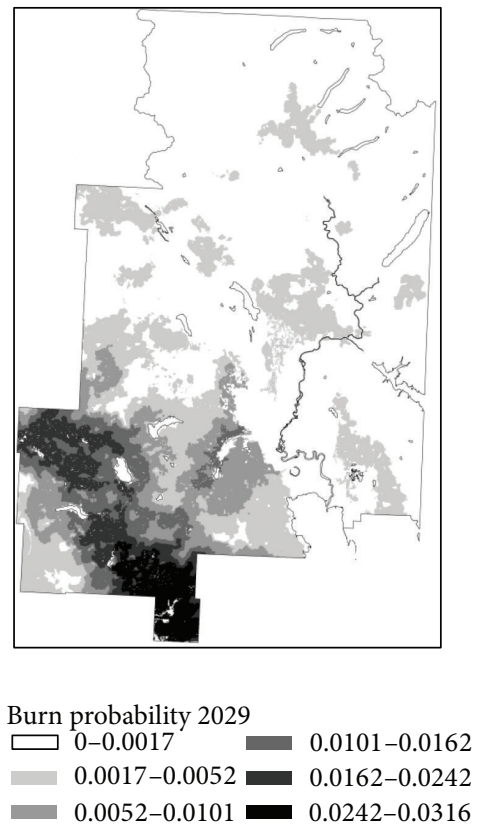

(c)

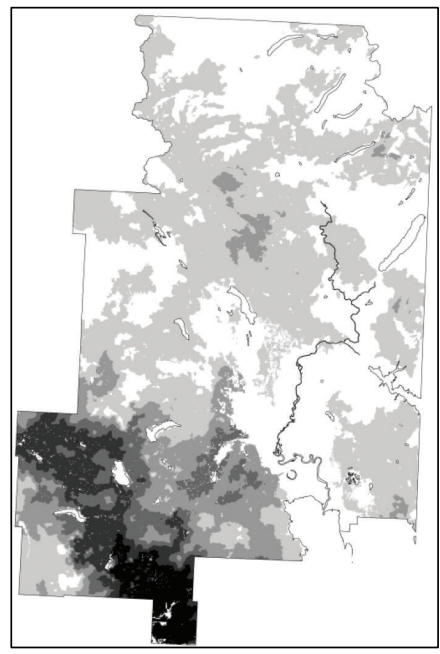

Burn probability 2059

$0-0.0017$
$0.0017-0.0052 \square 0.0101-0.0162$
$0.0052-0.0101 \square 0.0244-0.0316$

(f)

FIgURE 4: Subperiod simulated burn probabilities for developed parcels in Flathead County.

Simulated nominal and inflation-adjusted values of $\mathrm{E}(\mathrm{RLW})$ for all residential properties in the Flathead County WUI are reported in Table 3 . Results indicate that nominal $\mathrm{E}(\mathrm{RLW})$ increased monotonically from $\$ 1,836,816$ in $2000-$ 2009 to $\$ 33872,543$ in $2050-2059$, or $1,744 \%$. Present value in 2010 of, nominal E(RLW)s for the five subperiods is $\$ 11,420,778$ based on a nominal discount rate of $6 \%$. Inflationadjusted $\mathrm{E}(\mathrm{RLW})$ increased monotonically from $\$ 1,836,816$ in $2000-2009$ to $\$ 8,937,346$ in $2050-2059$, or $387 \%$. Peak increases in nominal and inflation-adjusted total E(RLW) occurred in 2020-2029 and amounted to $138 \%$ and $117 \%$, respectively.

Nominal weighted mean $\mathrm{E}(\mathrm{RLW})$ per residential property increased monotonically from $\$ 118$ in 20002009 to $\$ 805$ in $2050-2059$, or $582 \%$. Inflation-adjusted weighted mean $\mathrm{E}(\mathrm{RLW})$ per residential property increased nonmonotonically from \$118 in 2000-2009 to \$212 in 20502059 or 80 percent with decreases of 19\% from 2000-2009 
to 2010-2019 and $0.5 \%$ from 2040-2049 to 2050-2059.

No other published studies have developed and implemented a framework for simulating future values of E(RLW) for an alternative future. For that reason, it is not possible to compare the simulated values of $\mathrm{E}(\mathrm{RLW})$ presented in this study to the results obtained in other studies.

\section{Conclusion}

Uncertainty regarding future intertemporal changes in economic activity, climate, and land use policy poses a management challenge to forest managers and a potential threat to the long-term sustainability of forest ecosystems. Forest managers can meet the challenge and diminish the threat by adaptively managing the forests under their control for future economic growth and climate and land use changes. Unfortunately, the integrated conceptual framework needed to guide adaptive forest management decisions has been lacking. This paper proposes such a conceptual framework. The framework requires: (1) identifying feasible spatial patterns of forest management practices for consecutive subperiods; (2) specifying alternative futures each consisting of a unique combination of economic growth, climate change, and land use policy scenarios; (3) simulating the objectives attained by all feasible patterns in all subperiods; (4) having individual members of a forest management team or the team as a whole rate the simulated values of the objectives for all patterns and subperiods as well as the relative importance of the objectives; (5) using fuzzy TOPSIS to determine the preferred pattern for each subperiod and alternative future; and (6) utilizing the preferred patterns across subperiods to determine how best to adapt the patterns over subperiods for each alternative future.

This paper reports the results of a simulation of the inputs to and values of E(RLW) for the WUI for Flathead County, Montana, during the period 2010-2059. E(RLW) is one of the four management objectives for evaluating the efficacy of forest management practices specified in the conceptual framework. Simulation results indicate that there is substantial spatial variability in $\mathrm{E}(\mathrm{RLW})$ within the Flathead County WUI and substantial increases in simulated $\mathrm{E}$ (RLW) across the five, 10-year subperiods in the 2010-2059 planning horizon.

Application of the proposed conceptual framework is complex, a feature that would discourage most forest managers from using it. One way to increase forest managers' access to and use of the framework is to incorporate it in a web-based, interactive, spatial decision support system. The latter is a computer-based system that integrates data, information, and models for the purpose of allowing decisionmakers to solve complex, spatial decision problems and evaluate the consequences of alternative scenarios [49-51].

\section{Conflict of Interests}

The authors declare they have no conflict of interests regarding the publication of this paper.

\section{Acknowledgment}

The research on which this paper is based is supported in part by a grant from the Dynamics of Coupled Natural and Human Systems Program of the U.S. National Science Foundation, Award ID 0903562.

\section{References}

[1] M. J. Deuling, C. G. Woudsma, and S. E. Franklin, “Temporal analysis of habitat fragmentation: integrating GIS, landscape ecology, and improved RS classification methods," in Proceedings of the 4th International Conference on Integrating GIS and Environmental Modeling (GIS/EM4): Problems, Prospects, and Research Needs, Alberta, Canada, September 2000.

[2] B. Summerfield, W. Johnson, and D. Roberts, "Trends in road development and access management in the Cabinet-Yaak and Selkirk grizzly bear Recovery Zones," Ursus, vol. 15, no. 1, pp. 115-122, 2004

[3] C. I. Millar, N. L. Stephenson, and S. L. Stephens, "Climate change and forests of the future: Managing in the face of uncertainty," Ecological Applications, vol. 17, no. 8, pp. 2145-2151, 2007.

[4] R. W. Malmsheimer, P. Heffernan, S. Brink et al., "Forest management solutions for mitigating climate change in the United States," Journal of Forestry, vol. 106, no. 3, pp. 115-171, 2008.

[5] A. M. Evans and R. Perschel, "A review of forestry mitigation and adaptation strategies in the Northeast U.S," Climatic Change, vol. 96, no. 1, pp. 167-183, 2009.

[6] K. J. Puettmann, K. D. Coates, and C. C. Messier, A Critique of Silviculture: Managing for Complexity, Island Press, Washington, DC, USA, 2009.

[7] T. Prato, A. S. Clark, K. Dolle, and Y. Barnett, "Evaluating alternative economic growth rates and land use policies for Flathead County, Montana," Landscape and Urban Planning, vol. 83, no. 4, pp. 327-339, 2007.

[8] T. Prato, Y. Barnett, A. Clark, and T. Paveglio, "Improving simulation of land use change in a region of the Rocky Mountain West," in Land Use: Planning, Regulations, and Environment, C. Aubrecht, S. Freire, and K. Steinnocher, Eds., pp. 189-210, Nova Science Publishers, Hauppauge, NY, USA, 2012.

[9] C. Steinitz, Alternative Futures for Monroe County, Pennsylvania, Graduate School of Design, Harvard University, Cambridge, Mass, USA, 1993.

[10] C. Steinitz, An Alternative Future for the Region of Camp Pendleton, CaliFornia Graduate School of Design, Harvard University, Cambridge, Mass, USA, 1997.

[11] D. Hulse, J. Eilers, K. Freemark, C. Hummon, and D. White, "Planning alternative future landscapes in Oregon: evaluating effects on water quality and biodiversity," Landscape Journal, vol. 19, no. 1-2, pp. 1-19, 2000.

[12] J. P. Baker, D. W. Hulse, S. V. Gregory et al., "Alternative futures for the Willamette River Basin, Oregon," Ecological Applications, vol. 14, no. 2, pp. 313-324, 2004.

[13] C. Steinitz, H. Arias, S. Bassett et al., Alternative Futures for Changing Landscapes: the upper San Pedro River Basin in Arizona and Sonora, Island Press, Washington, DC, USA, 2003.

[14] G. D. Peterson, T. D. Beard Jr., B. E. Beisner et al., "Assessing future ecosystem services: a case study of the Northern Highlands Lake District, Wisconsin," Conservation Ecology, vol. 7, no. 3, article 1, 2003. 
[15] Minnesota IMPLAN Group, Inc., IMPLAN System (data and software), Stillwater, Minn, USA, 2013, http://www.implan .com.

[16] US Department of Agriculture and US Department of the Interior, "Urban wildland interface communities within the vicinity of federal lands that are at high risk from wildfire," Federal Register, pp. 43384-43435, 2001.

[17] S. I. Stewart, B. Wilmer, R. B. Hammer et al., "Wildlandurban interface maps vary with purpose and context," Journal of Forestry, vol. 107, no. 2, pp. 78-83, 2009.

[18] Intergovernmental Panel on Climate Change (IPCC), "IPCC's 4th assessment report, climate change 2007," Synthesis Report, 2007, http://www.ipcc.ch/pdf/assessment-report/ar4/ syr/ar4_syr_spm.pdf.

[19] Intergovernmental Panel on Climate Change (IPCC), IPCC's 5th assessment report, 2012, http://www.ipcc.ch/.

[20] "World climate change research program," CMIP5 Coupled Model Intercomparison Project, 2011, http://cmip-pcmdi.llnl .gov/cmip5/.

[21] A. W. Wood, L. R. Leung, V. Sridhar, and D. P. Lettenmaier, "Hydrologic implications of dynamical and statistical approaches to downscaling climate model outputs," Climatic Change, vol. 62, no. 1-3, pp. 189-216, 2004.

[22] A. W. Wood, E. P. Maurer, A. Kumar, and D. P. Lettenmaier, "Long-range experimental hydrologic forecasting for the eastern United States," Journal of Geophysical Research D, vol. 107, no. 20, p. 4429, 2002.

[23] G. A. Meehl, C. Covey, T. Delworth et al., "The WCRP CMIP3 multimodel dataset: a new era in climatic change research," Bulletin of the American Meteorological Society, vol. 88, no. 9, pp. 1383-1394, 2007.

[24] S. M. McGinn, A. Touré, O. O. Akinremi, D. J. Major, and A. G. Barr, "Agroclimate and crop response to climate change in Alberta, Canada," Outlook on Agriculture, vol. 28, no. 1, pp. 1928, 1999.

[25] C. L. Hwang and K. Yoon, Multiple Attribute Decision Making, vol. 186 of Lecture Notes in Economics and Mathematical Systems, Springer, Berlin, Germany, 1981.

[26] S. J. Chen and C. L. Hwang, Fuzzy Multiple Attribute Decision Making, vol. 375 of Lecture Notes in Economics and Mathematical Systems, Springer, Berlin, Germany, 1992.

[27] C. T. Chen, "Extensions of the TOPSIS for group decisionmaking under fuzzy environment," Fuzzy Sets and Systems, vol. 114, no. 1, pp. 1-9, 2000.

[28] P. A. Berger, "Generating agricultural landscapes for alternative futures analysis: a multiple attribute decision-making model," Transactions in GIS, vol. 10, no. 1, pp. 103-120, 2006.

[29] T. Prato and S. Hajkowicz, "Comparison of profit maximization and multiple criteria models for selecting farming systems," Journal of Soil and Water Conservation, vol. 56, no. 1, pp. 52-55, 2001.

[30] T. Prato, "Multiple-attribute evaluation of ecosystem management for the Missouri River system," Ecological Economics, vol. 45, no. 2, pp. 297-309, 2003.

[31] T. Prato, "Fuzzy multiple attribute evaluation of alternative land use futures," Journal of Land Use Science, vol. 4, no. 3, pp. 201213, 2009.

[32] T. Prato, "Increasing resilience of natural protected areas to future climate change: a fuzzy adaptive management approach," Ecological Modelling, vol. 242, pp. 46-53, 2012.
[33] R. E. Keane, R. A. Loehman, and L. M. Holsinger, "The FireBGCv2 landscape fire succession model: a research simulation platform for exploring fire and vegetation dynamics,' USDA Forest Service, Rocky Mountain Research Station General Technical Report RMRS-GTR-255, 2011.

[34] M. A. Finney, “2007," A prototype simulation system for large fire planning in FPA, Missoula, Mont, USA, 2002, http://www.fpa.nifc.gov/Library/Docs/FPA_SimulationPrototype_0705.pdf.

[35] T. Prato, T. B. Paveglio, Y. Barnett et al., "Simulating future residential property losses from wildfire in Flathead County, Montana," in Advances in Environmental Research, Nova Science Publishers, Hauppauge, NY, USA.

[36] K. M. Stetler, T. J. Venn, and D. E. Calkin, "The effects of wildfire and environmental amenities on property values in northwest Montana, USA," Ecological Economics, vol. 69, no. 11, pp. 22332243, 2010.

[37] M. A. Finney, I. C. Grenfell, C. W. McHugh et al., "A method for ensemble wildland fire simulation," Environmental Modeling and Assessment, vol. 16, no. 2, pp. 153-167, 2011.

[38] X. Li, M. H. Nour, D. W. Smith, E. E. Prepas, G. Putz, and B. M. Watson, "Incorporating water quantity and quality modelling into forest management," Forestry Chronicle, vol. 84, no. 3, pp. 338-348, 2008.

[39] R. A. Logsdon and I. Chaubey, "A quantitative approach to evaluating ecosystem services," Ecological Modelling, vol. 257, no. 24, pp. 57-65, 2013.

[40] S. W. Hayes, C. E. Keegan III, and T. A. Morgan, Estimating Harvesting Costs, Bureau of Business and Economic Research, University of Montana, 2012,http://www.bber.umt.edu/pubs/ forest/prices/loggingCostPost- er2011.pdf.

[41] C. Moritz, J. L. Patton, C. J. Conroy, J. L. Parra, G. C. White, and S. R. Beissinger, "Impact of a century of climate change on small-mammal communities in Yosemite National Park, USA," Science, vol. 322, no. 5899, pp. 261-264, 2008.

[42] D. E. Capen, L. Osborn, S. MacFaden, and R. Sims, Mapping Wildlife Habitat in the Lewis Creek Watershed, Spatial Analysis Laboratory, University of Vermont, 2002, http://www.uvm.edu/rsenr/sal/ lewiscreek.html.

[43] V. C. Radeloff, D. J. Mladenoff, E. J. Gustafson et al., "Modeling forest harvesting effects on landscape pattern in the Northwest Wisconsin Pine Barrens," Forest Ecology and Management, vol. 236, no. 1, pp. 113-126, 2006.

[44] K. McGarigal, S. A. Cushman, and E. Ene, "FRAGSTATS v4: spatial pattern analysis program for categorical and continuous maps," Computer software program produced by the authors at the University of Massachusetts, Amherst, Mass, USA, 2012, http://www.umass.edu/landeco/research/fragstats/ fragstats.html.

[45] B. DeZonia and D. J. Mladenoff, APACK 2.22 User's Guide Version 5-6-02, Department of Forest Ecology and Management, University of Wisconsin-Madison, Madison, Wis, USA, 2002.

[46] D. Thoma and H. Shovic, "Using landscape patterns, climate projections, and species distribution models to map future potential habitats for desert tortoise, Shivwits milk-vetch, and American pika in Zion National Park, Utah," Park Science, vol. 29, no. 2, pp. 14-22, 2013.

[47] K. N. Lee, Compass and Gyroscope: Integrating Science and Politics for the Environment, Island Press, Washington, DC, USA, 1993. 
[48] K. A. Kohm and J. F. Franklin, "Introduction," in Creating Forestry for the 21st Century: The Science of Ecosystem Management, K. A. Kohm and J. F. Franklin, Eds., pp. 1-5, Island Press, Washington, DC, USA, 1997.

[49] D. Djokic, "Towards general purpose spatial decision support systems using existing technologies," in Proceedings of the 2nd International Conference/Workshop on Integrating Geographic Information Systems and Environmental Modeling, Breckenridge, Colo, USA, September 1993.

[50] D. P. Loucks, "Developing and implementing decision support systems: a critique and a challenge," Water Resources Bulletin, vol. 31, no. 4, pp. 571-582, 1995.

[51] R. Sugumaran and J. Degroote, Spatial Decision Support Systems: Principles and Practices, CRC Press, Boca Raton, Fla, USA, 2010. 

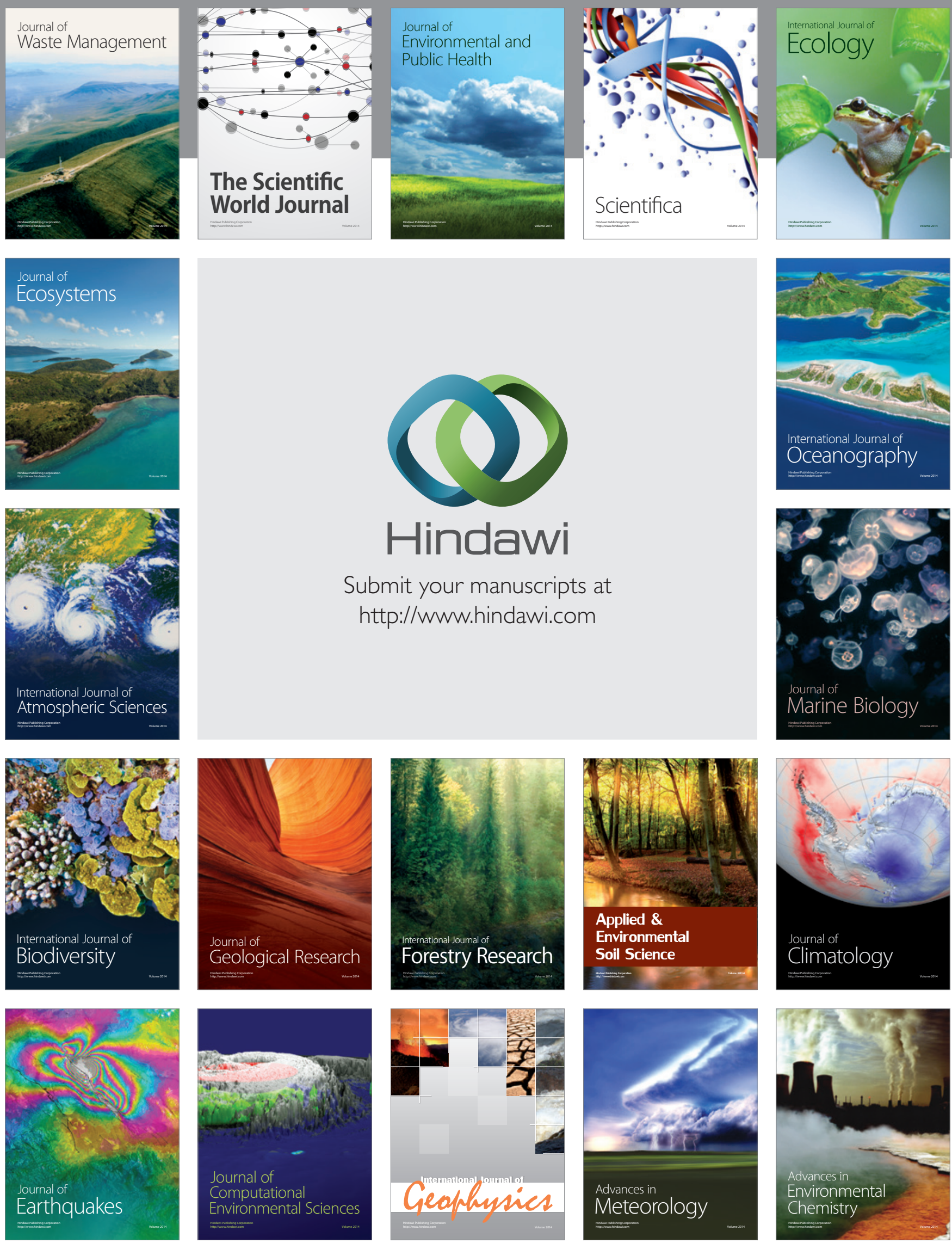